\title{
To Recall or Not to Recall a Flawed Product: Corporate Responses and Consumer Perceptions of Toy Recalls ${ }^{*}$
}

\author{
William H. Murphy, Monica M. Popa \\ University of Saskatchewan, Saskatoon, Canada
}

\begin{abstract}
Examining parents' reactions to incidents involving toy defects, the authors find that corporate strategies of handling product problems influence consumer attitudes and purchase intentions, and beneficial effects of recalling a product can arise for firms, particularly when the product problem is minor and the company response is strong. This research emphasizes that product recalls can be viewed not only from the disaster-mitigation perspective of prior literature, but also as opportunities for companies to realize market benefits by engaging in responsible recall behavior, forging better relationships with customers. Additionally, the authors find that individuals' search for information following recall news is dependent on the product defect encountered.
\end{abstract}

Keywords: attitudes, perceptions, purchase intentions, product recall, consumer protections

\section{Introduction}

The surge of product recall incidents in recent years has triggered increased research attention to the effects of recalls on consumer perceptions and market performance. Such research is anchored in the product failure literature (Dawar \& Pillutla, 2000; Darke, Ashworth, \& Main, 2010; Folkes, 1984; Wang, Liang, \& Peracchio, 2011), which indicates that consumer reactions to faulty products depend on their interpretations of company responsibility. Specifically, negative consumer perceptions arise after a recall announcement, but the negative impact can be diminished if there is brand familiarity and if perceptions of company responsibility for the failure are low (De Matos \& Rossi, 2007; Mowen, Jolly, \& Nickell, 1981; Siomkos \& Kurzbard, 1994).

The current study extends this work by proposing that product recalls can be viewed not only from the disaster-mitigation perspective, but also as opportunities for firms to realize market benefits by forging better relationships with customers. This present study shows that, even in situations of products with major problems for which the company is responsible, a well-handled recall can shield the brand from damaging effects, and more importantly, those recalls for minor defects produce benefits that outweigh costs to the brand, increasing rather than decreasing individuals' likelihood to buy products from the company in the future. This implies that, contrary to common beliefs, certain types of recalls are actually advantageous for firms in terms of brand

\footnotetext{
*Acknowledgement: The authors wish to thank Karen Tangen and Haydee Iglesias for their assistance at the early stages of this research.

William H. Murphy, Ph.D., associate professor, Hanlon Scholar in International Business, Edwards School of Business, University of Saskatchewan.

Monica M. Popa, Ph.D., assistant professor, Edwards School of Business, University of Saskatchewan.
} 
perceptions.

Beyond the general shift in perspective substantiated by intriguing findings, this study offers a number of theoretical and practical contributions. First, the authors are bringing the research forefront an important factor previously unexplored in recall studies: the type of product problem (i.e., major vs. minor problems). The level of perceived product danger has been identified as noteworthy for consumers (Dawar \& Pillutla, 2000; Siomkos \& Kurzbard, 1994), but existing research has explored major problems that pose life-threatening or at least serious risks of injury and general harm. Minor problems, whereby the product's potential to harm individuals is low, have not been explicitly studied, perhaps due to researchers' assumptions that effects on attitudes and purchase behaviors would be negligible. For businesses, there may be a parallel assumption that defects or quality problems with minor consumer consequences would not justify the costs associated with a recall (as it would bring unnecessary/unwanted publicity to the problem). However, this study indicates that such assumptions are unwarranted.

Second, the authors investigate the neglected aspect of consumer information search following recall news. Prior studies have typically exposed participants to product recall scenarios, examining reactions to the information provided (Dawar \& Pillutla, 2000; Klein \& Dawar, 2004; Siomkos \& Kurzbard, 1994). However, the possibility that consumers might search for additional information after reading a recall announcement has not been taken into account. The paucity of the literature is puzzling, as individuals may not limit themselves to being passive receivers of recall news, and whether or not they search for information may have important implications for their responses to recalls.

Third, the authors' work extends the product recall literature to a category (children's toys) that has yet to receive theoretical attention. While a number of recall studies have focused on expensive products associated with high involvement (e.g., automobiles) (De Matos \& Rossi, 2007; Hoffer, Pruitt, \& Reilly, 1994), children’s toys represent an interesting category since these products are not big-ticket items but still involve safety concerns (as Mattel, the world's largest toy-maker, has learned from its recalls of faulty toys (Ainsworth-Vincze, 2010). The global toy industry, generating over \$78 billion in 2008 (ICTI, 2008) takes children as a major market. Society appropriately views children as a vulnerable consumer segment that needs amplified protection, and parents expect and seek safe options for their little ones. Unfortunately, problems in children's products are a common occurrence, as evidenced by the records of the Consumer Product Safety Commission (the U.S. Federal Agency that oversees the safety of consumer products), where recalls of hundreds of toys and infant products are adding up to tens of millions of units (Felcher, 2003). Surprisingly, given the implications of these products for children and the plethora of news articles, statistics, and reports of toy recall incidents (e.g., Casey \& Zamiska, 2007; McIlroy, 2007; Xu, 2010; Warner, 2008), theoretical or empirical studies on this topic are lacking. The authors address the research gap by surveying North American parents with young children to elucidate their perceptions of toy recalls.

\section{Conceptual Development}

\section{Product Problems and Consumer Information Search}

The product recall literature indicates that negative consumer reactions toward companies can arise upon 
reading a recall announcement (Bechwati \& Morrin, 2003; De Matos \& Rossi, 2007; Jolly \& Mowen, 1985; Mowen, 1980; Schoeny, 1992; Siomkos \& Kurzbard, 1994). This literature has predominantly focused on consumer buying intentions and impressions of the company or the product. In today's information-rich environment (where consumers are able to access an astonishing array of information online or offline), it is surprising that the literature has not studied other variables, such as consumer likelihood to search for information after hearing about a product recall. Once exposed to recall information, consumers can experience one of the two effects. On the one hand, they may desire more information and actively engage in search behavior. Pursuit of additional information may be generated by consumer unease about company claims, due to perceptions that the current response is insufficient, or a past history of disconfirmations. On the other hand, consumers can be satisfied with the company's way of dealing with the problem, thus feeling no need for information search. Consumers may also decide not to search for information in order to: (1) save time, (2) minimize cognitive effort, and (3) avoid recall fatigue (i.e., in a world where recalls are announced on a daily basis across numerous product categories, the next in a long line of recalls may not provoke active information search).

While such possibilities are largely speculations given the lack of theoretical or empirical support in this area, an argument can be made that consumer search for information will depend on the type of problem (major vs. minor) that generates the product recall. The authors draw from the literature on risk perceptions, which indicates that defective/dangerous products with major problems generate product-harm crises (Dawar \& Pillutla, 2000) and are perceived by consumers as highly risky (De Matos \& Rossi, 2007). Perceptions of risk have been shown to influence the extent of information search, such that consumers are more likely to search when perceived risk is high rather than low (Solomon, Zaichkowsky, \& Polegato, 2009). Corroborating the above insights, the authors predict that:

H1 (Hypothesis 1): A major (vs. minor) defect announced during a product recall will increase consumer likelihood to engage in information search.

\section{Company Responses to Product Problems and Consumer Attitudes}

When faced with product crises, companies will reap rewards or penalties depending on their chosen response strategies. Decisions must be made swiftly, as these decisions affect reputation, media direction and intensity, and the possibility of consumer backlash (Siomkos \& Kurzbard, 1994). The types of company responses to product defects can range from weak to strong depending on whether the company takes responsibility for the problem, whether the recall is forced by an external organization (e.g., government) or is voluntarily initiated by the company, whether the company is honest and transparent in its communication, and whether the firm demonstrates genuine concern with consumer welfare by making the recall process very easy for consumers and by seeking measures to prevent problems from happening again (Jolly \& Mowen, 1985; Shrivastavas \& Siomkos, 1989). Taking these factors into account, Siomkos and Kurzbard (1994) have classified company responses into four categories: denial, involuntary recall, voluntary recall, and super-effort. The authors construe the first two response types as weak responses, and the latter types as strong responses.

A strong as opposed to a weak company response to product problems can be expected to have a more positive effect on consumer attitudes, based on several reasons. First, a strong response occurs when the 
company takes responsibility for the problem, and consumers tend to have more positive attitudes toward firms perceived as responsible and honest (De Matos \& Rossi, 2007). Second, a strong response entails both a proactive identification of the product problem (e.g., the problem being discovered during in-house quality controls), and voluntary engagement in recall action before an external organization or negative publicity forces the company to do so. Based on existing studies, such company responses can be expected to have a positive impact on individuals' impressions of the firm (Siomkos \& Kurzbard, 1994; Jolly \& Mowen, 1985). Third, a strong response can encompass corrective changes in production practices accompanied by statements of action to consumers, including assurance that future problems will be prevented. These actions, viewed as a form of corporate social responsibility, have a positive influence on individuals' evaluations of the company after a product crisis (Klein \& Dawar, 2004). Based on these arguments, the authors predict that:

H2 (Hypothesis 2): A strong (vs. weak) company response to a product problem will have a positive effect on individuals' attitudes toward the company.

\section{Purchase Intentions as a Function of Product Problem and Company Response}

As noted above, company responses in recall situations are likely to affect brand image and attitudes toward the company. In turn, consumers' attitudes can have carry-over effects on purchase intentions (Griffin, Babin, \& Attaway, 1991). In the context of product recalls, there are various reasons to believe that company response strategies will impact not just attitudes, but also purchase intentions. Specifically, Souiden and Pons (2009) indicated that a firm's crisis management has a positive effect on individuals' loyalty and intentions to buy from the company in the future. Also, Dawar and Pillutla (2000) demonstrated that perceptions of responsible firm's behavior predict individuals' post-crisis intentions to purchase. Furthermore, Siomkos and Kurzbard (1994) found that a company's response to a product crisis influences consumer future purchases from the company. Therefore, the authors expect that:

H3 (Hypothesis 3): A strong (vs. weak) company response during a product recall event will have a positive effect on individuals' likelihood to buy products from the company.

A major (vs. minor) product problem entails a higher perceived risk for consumers due to the serious harm that can arise as a result of using the faulty product. In turn, the perceived danger associated with a product has been found to have an inverse relationship with consumer behavioral intentions (De Matos \& Rosi, 2007). Specifically, when the defect presented in the recall message generates a higher level of perceived danger, people manifest lower behavioral intentions toward the brand recalled. Taken this together with Ahluwalia and Gürhan-Canli's (2000) observation that product failures have negative carry-over effects on other products of the company, the authors put forward the following hypothesis:

H4 (Hypothesis 4): A product recall event for a major (vs. minor) product defect will have a negative effect on individuals' likelihood to buy products from the company.

\section{Method}

One hundred and five parents from U.S. and Canada participated in this 2 (product problem: major vs. minor) $\times 2$ (company response: strong $v$ s. weak) between-subjects study. Participants were prescreened to have at least one child under 12 years old. These parents answered the invitation to complete a survey and were 
offered a chance to win a $\$ 50$ gift certificate for their participation. The survey instrument was pretested with an independent sample of eight parents to ensure the clarity and appropriateness of questions. In the main study, participants were provided with information about a company's recall announcement that included the following description:

In the past, you have purchased toys from XYZ Company, and overall, you have been pleased with their products. You are planning to purchase another toy from XYZ Company for your child. You have just seen the following headline on your online homepage: "Toy Recall: XYZ Company recalls 20,000 units of popular..." You open the article and the following excerpt "sticks" in your mind: "On February 1st, 2010, XYZ Company announced that... They are recalling 20,000 units (of their popular 'Fun Toy') produced after January 1st, 2010.” Spokesperson Josh Petson states...

The spokesperson's statement and information about the recall were used for the manipulations of product problem (major vs. minor) and company response (strong vs. weak). In the "major problem" condition, participants read that the recall was due to "a major issue with regards to potential shards' breaking off, causing harm to eyes or potential choking hazard. Five children have been admitted to hospital with serious injuries related to the product defect". In the "minor problem" condition, participants read that the recall was due to a minor, non-life threatening issue related to the quality of plush utilized, which made the toy less soft than it was supposed to be.

In the "strong company response" condition, participants read that the product problem was discovered by the company, with a spokesperson stating that, "We regularly check our quality and safety at XYZ Company. The latest results indicate a (problem). This led to our immediate recall of these products. We are taking full responsibility and will be reporting on the steps being taken to prevent this from happening again”. In the "weak company response" condition, participants read that the product problem was discovered by a reporter, and the company's spokesperson simply stated that, "We stand by our products. We have no further comments at this time”.

Each participant was randomly assigned to one of the four experimental conditions. Upon reading the recall announcement, participants indicated the extent to which they would do more research into the situation, on a five-point scale (definitely would not look into it/definitely would look into it). Attitudes toward the company were assessed by asking participants how they would think of the company after reading about the recall as compared to before (much worse/somewhat worse/about the same/somewhat more highly/much more highly). Participants' likelihood to buy products from the company was also measured on a five-point scale, with the following question: If after reading about the recall you were to go shopping for a toy for your child(ren), would you: (1) definitely stay away from toys made by this company? (2) probably stay away from toys made by this company? (3) be unsure about my buying behavior towards toys made by this company? (4) somewhat likely consider buying toys made by this company? or (5) definitely consider buying toys made by this company? Finally, participants were asked demographic questions (age, gender, employment status, income, housing arrangements, and education)?

\section{Sample Characteristics}

The sample was comprised of $17 \%$ males and $83 \%$ females. The majority of participants (84.8\%) were 
raising their child(ren) with another adult in their home, $7.6 \%$ were single parents, and $7.6 \%$ lived in a home with three or more adults. Regarding employment status, $45 \%$ of participants were employed full-time while $32 \%$ were stay at home parents; the remaining $21 \%$ and $2 \%$ were employed part-time or unemployed, respectively. In terms of age, 53.3\% of respondents were between 25 and 35 years old, 35.2\% of participants were in the $36-65$ age bracket, and $11.5 \%$ of the sample consisted of 18-24 years old. Based on household income, $40.8 \%$ of participants were earning $\$ 75,000$ or more, $28.2 \%$ were earning between $\$ 20,000-\$ 49,000$, $26.1 \%$ were earning $\$ 50,000-\$ 74,999$, and $4.9 \%$ were earning $\$ 0-\$ 19,999$. Participants’ levels of education were also quite diverse, with $38.1 \%$ of them having some university/college education, $17.1 \%$ with a college certificate/diploma, $10.4 \%$ with a high school diploma, $20 \%$ with a bachelor degree, $8.6 \%$ with a master degree, $2.9 \%$ with doctorates, and $2.9 \%$ with no high school degree.

\section{Results}

\section{Information Search Behavior}

A 2 (product problem: major vs. minor) $\times 2$ (company response: strong vs. weak) ANOVA (analysis of variance) with consumer likelihood to engage in information search as the dependent variable revealed a significant main effect of product problem: A major (vs. minor) problem announced in a product recall increases consumer likelihood to do more research into the situation $\left(M_{\text {major }}=4.18, M_{\text {minor }}=3.20, F_{(1,101)}=\right.$ 19.80, $p=0.000$ (see Figure 1). Thus, H1 is supported.

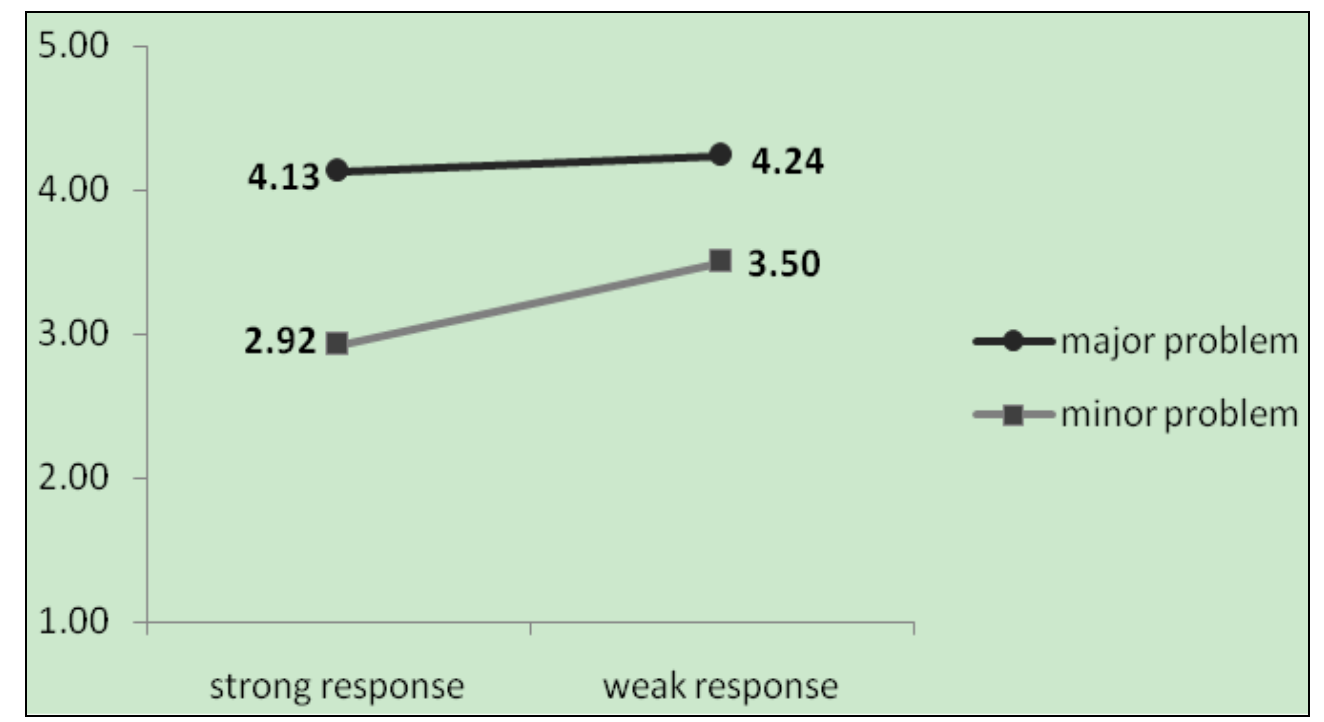

Figure 1. Consumer likelihood to engage in information search after reading the product recall announcement.

\section{Attitudes Toward the Company}

A 2 (product problem) $\times 2$ (company response) ANOVA testing consumer attitudes toward the company after reading the recall announcement produced a significant main effect of company response: Participants' attitudes were more positive when the firm had a strong rather than weak response to the problem $\left(M_{\text {strong }}=\right.$ 3.04, $M_{\text {weak }}=2.27, F_{(1,101)}=19.32, p=0.000$ ) (see Figure 2). Therefore, $\mathrm{H} 2$ is supported. 


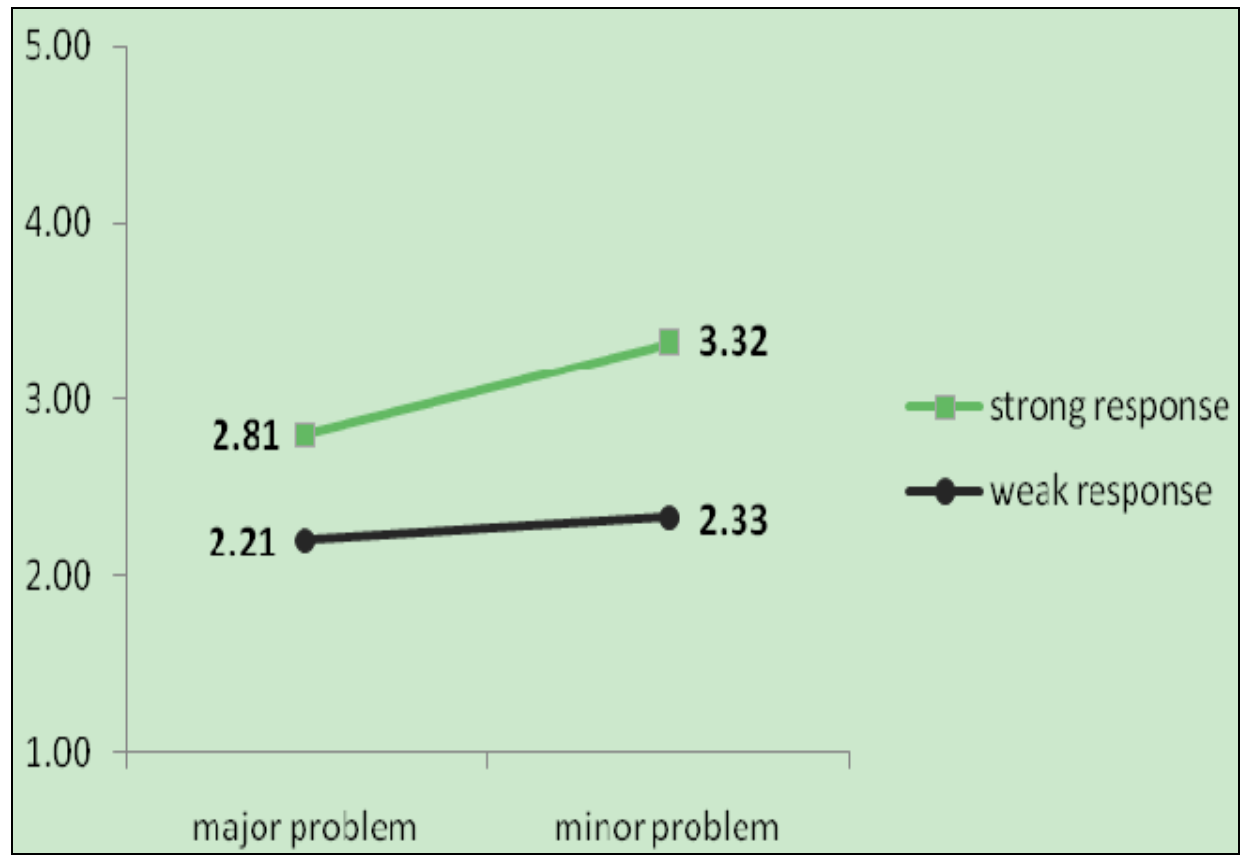

Figure 2. Consumer attitudes toward the company after reading the product recall announcement.

Importantly, two-tailed $t$-tests for means comparisons indicated that the experimental condition with a minor problem and strong company response $\left(M_{\text {minor_strong }}=3.32\right)$ generated significantly more positive attitudes compared to each of the other three conditions $\left(M_{\text {minor_weak }}=2.33, t=3.78, p=0.000 ; M_{\text {major_strong }}=\right.$ $2.81, t=2.09, p=0.04 ; M_{\text {major_weak }}=2.21, t=4.26, p=0.000$ ). Furthermore, there was a significant positive difference between the strong and the weak company responses in the case of a major product problem $\left(M_{\text {major_strong }}=2.81, M_{\text {major_weak }}=2.21, t=2.41, p=0.018\right)$.

Comparing the mean value in each condition with the neutral point (in this case the mid-point of the scale, $M=3.0$ ) using simple $t$-tests, the authors found a significant positive difference in the case of a minor problem and strong company response $(t=2.32, p=0.029)$, significant negative differences in the case of a minor problem and weak company response $(t=5.13, p=0.000)$, and major problem with weak company response ( $t$ $=3.52, p=0.002$ ), as well as a non-significant difference for the major problem and strong company response condition $(t=1.00, p=0.325)$.

\section{Purchase Intentions}

A 2 (product problem) $\times 2$ (company response) ANOVA, testing consumer likelihood to buy products from the company after reading the recall announcement, revealed a positive main effect of company response. As predicted by H3, participants' purchase intentions were higher when the firm had a strong rather than weak response to the problem $\left(M_{\text {strong }}=3.05, M_{\text {weak }}=2.20, F_{(1,101)}=26.33, p=0.000\right)$ (see Figure 3). The ANOVA results also showed a main effect of product problem, indicating that participants' purchase intentions were lower when a major $v$ s. minor problem was announced during the recall $\left(M_{\text {major }}=2.29, M_{\text {minor }}=3.08, F_{(1,101)}=\right.$ 22.31, $p=0.000$ ). Thus, $\mathrm{H} 4$ is also supported.

Analyses of purchase intentions using two-tailed $t$-tests for means comparisons revealed that the experimental condition with a minor problem and strong company response $\left(M_{\text {minor_strong }}=3.60\right)$ generated 
higher purchase intentions compared to each of the other three conditions $\left(M_{\text {minor_weak }}=2.54, t=4.16, p=\right.$ 0.000; $M_{\text {major_strong }}=2.61, t=4.13, p=0.000 ; M_{\text {major_weak }}=1.88, t=6.84, p=0.000$ ). Also, there was a significant positive difference between the strong and the weak company responses in the case of a major product problem $\left(M_{\text {major_strong }}=2.61, M_{\text {major_weak }}=1.88, t=3.06, p=0.003\right)$.

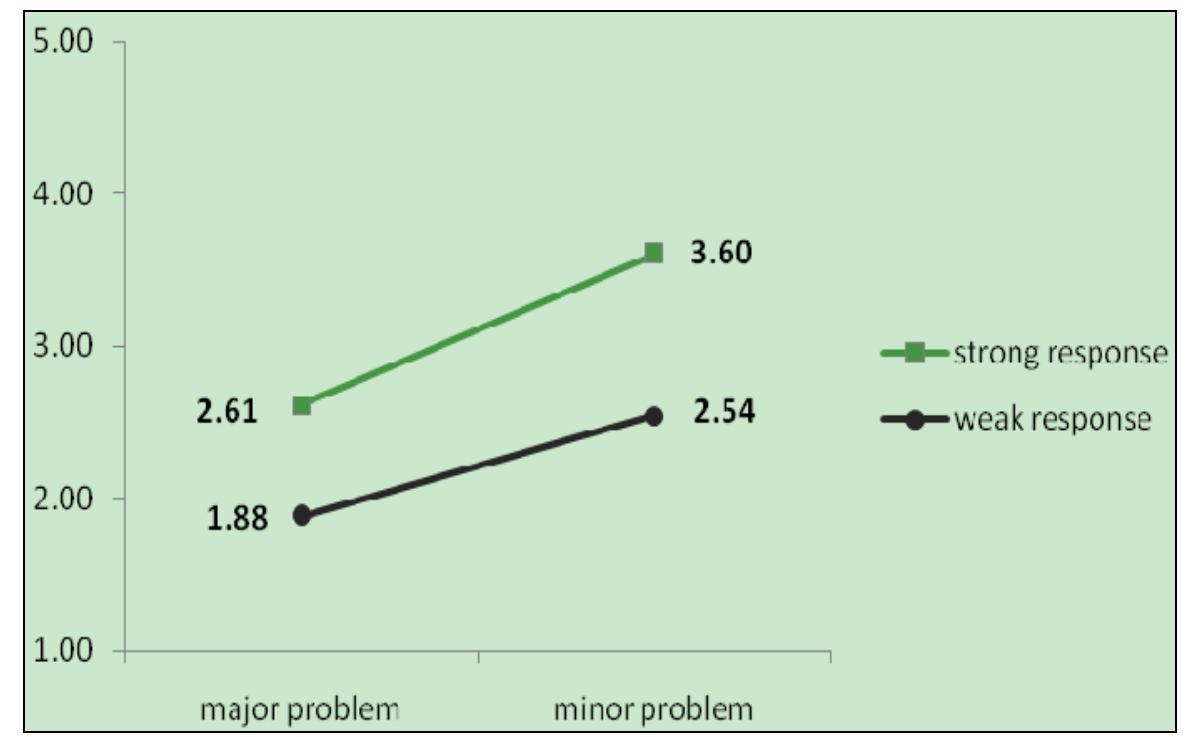

Figure 3. Consumer likelihood to buy products from the company after reading the product recall announcement.

Comparing the mean value in each condition with the neutral point (in this case, the mid-point of the scale, $M=3.0$ ) using simple $t$-tests, the authors found a significant positive difference in the case of a minor problem and strong company response $(t=3.46, p=0.002)$, and significant negative differences for the conditions with major problem and weak company response $(t=6.73, p=0.000)$, minor problem and weak company response $(t=2.41, p=0.024)$, and major problem with strong company response $(t=2.34, p=0.026)$.

\section{Additional Results}

For each of the previously reported models using information search behavior, attitudes toward the company, and purchase intentions as dependent variables, demographic variables were added one at a time to the 2 (product problem) $\times 2$ (company response) ANOVAs. These analyses produced no significant effects for gender, age, education, employment status, income, or housing arrangements.

\section{Discussion and Implications}

Despite the numerous high-profile incidents where children's wellbeing has been threatened due to toy defects, the literature on product recalls has not offered experimental studies to examine the consequences of toy recalls on consumer perceptions. The authors address this research gap and show that although consumer attitudes and purchase intentions can be negatively affected by toy recalls, company responses are able to mitigate consumer reactions. This research also goes beyond exploring major product problems (i.e., those with substantial potential for harm) to include minor incidents and their effects on consumers. Whereas many businesses may presume that harmless product defects do not justify the costs associated with a recall, these 
research findings indicate that these types of recalls can provide a significant uplift in brand attitudes and purchase intentions.

The authors also examine whether the nature of company response (strong vs. weak) to product problems influences consumer reactions. In line with prior literature in other product recall situations (e.g., automobiles), the authors find that strong corporate responses have a consistently more positive effect on consumer attitudes and purchase intentions than weak corporate responses. However, these research findings also suggest that dealing with a product problem via recalls is appropriate even for minor defects, as this sends powerful signals regarding the vigilance of the brand. When the firm recalls a product due to defects that are not life-threatening or harmful, consumers may interpret the action as a sign of extra care and responsibility on the part of the company, suggestively high-quality standards. This could explain the positive effect on purchase intentions the authors observed in the minor/strong condition.

In terms of consumer information search patterns, the authors find that news about toy recalls for major (vs. minor) defects are less likely to be information satiating. Further, this finding is not affected by the type of response (strong vs. weak) adopted by the company. This implies that firms should not consider an incident resolved following an initial response to the problem. Instead, layers of responses are needed, i.e., activating multiple communication channels to reinforce company messaging consistent with the initial consumer exposure to recall information.

The authors included a number of demographic variables in this study as a way to discern whether factors, such as gender, age, education, and income, can be used to anticipate differences in consumer response to toy recall events. None of the demographics had a significant effect on information search, attitudes, or purchase intentions, suggesting that parents are essentially the same when it comes to concerns with the wellbeing of their children.

This research opens up a number of new directions for scholarly pursuit. First, while the authors demonstrate that the disaster-mitigation perspective is not necessarily warranted in the context of toy recalls, future research can explore if beneficial effects of product recalls can be obtained in other industries beyond children's toys. Second, while the authors measure consumer purchase intentions following recall announcements, future research could focus on how intentions translate into buying behavior. The present work is the first step toward understanding the effects of recalls for minor defects, emphasizing that such recalls can be viable options for business strategists. Future research could test the process mechanism responsible for the positive effect, and explore what happens when minor recalls become a generalized practice. Specifically, although consumers have positive reactions to minor-defect recalls, reactions may change if such recalls are abused by the company or if all companies in the industry adopt this strategy. A company that repeatedly recalls products for minor defects may end up being perceived as incompetent (instead of customer-focused). Also, if all companies in the industry are starting to use minor-defect recalls, consumers may no longer view the recall of a specific firm as a sign of paying extra care and attention to ensure high-quality standards. Finally, while the authors find no differences in consumer reactions to toy recalls based on demographic variables, personality characteristics, such as individuals' level of skepticism/suspicion may play a role in recall perceptions. Future research could determine whether this is actually the case. 


\section{Conclusions}

By examining parents' attitudes and perceptions of product problems in the children's toys context, this study reveals beneficial market effects of recalling a product, prompting managers to think twice before opting out of voluntary recalls. This insight is critically important in the modern business landscape. Governments and consumer protection organizations are faced with a surge of product problems that require intervention. In practice, relying on regulators to protect consumers is "largely post hoc, not preventative" (Felcher, 2003). Offering evidence to firms that proactive voluntary recall is not only the right thing to do, but also the profitable/efficient thing to do, may improve consumer welfare and diminish regulatory burden. This would translate into a win-win-win situation for individuals, governments, and companies. This research provides much-needed evidence that could contribute to a better business and social environment.

\section{References}

Ahluwalia, R., \& Gürhan-Canli, Z. (2000). The effects of extensions on the family brand name: An accessibility-diagnosticity perspective. Journal of Marketing Research, 27, 371-381.

Ainsworth-Vincze, C. (2010). Retail: Spinning a toy story. Maclean's, 123(40), 59-60.

Bechwati, N. N., \& Morrin, M. (2003). Outraged consumers: Getting even at the expense of getting a good deal. Journal of Consumer Psychology, 13(4), 440-453.

Casey, N., \& Zamiska, N. (2007, August 15). Mattel does damage control after new recall; Toy maker pledges to boost inspection at Chinese plants; Sarge cars, Barbie affected. Wall Street Journal (Eastern Edition), B1.

Darke, P. R., Ashworth, L., \& Main, K. J. (2010). Great expectations and broken promises: Misleading claims, product failure, expectancy disconfirmation and consumer distrust. Journal of the Academy of Marketing Science, 38, 347-362.

Dawar, N., \& Pillutla, M. M. (2000). Impact of product-harm crises on brand equity: The moderating role of consumer expectations. Journal of Marketing Research, 37, 215-226.

De Matos, A. C., \& Rossi, C. A. V. (2007). Consumer reaction to product recalls: Factors influencing product judgement and behavioural intentions. International Journal of Consumer Studies, 31, 109-116.

Felcher, M. E. (2003). Product recalls: Gaping holes in the nation's product safety net. Journal of Consumer Affairs, 37(1), 170-179.

Folkes, V. S. (1984). Consumer reactions to product failure: An attributional approach. Journal of Consumer Research, 10(March), 398-409.

Griffin, M., Babin, B. J., \& Attaway, J. S. (1991). An empirical investigation of the impact of negative public publicity on consumer attitudes and intentions. Advances in Consumer Research, 18, 334-341.

Hoffer, G. E., Pruitt, S. W., \& Reilly, R. J. (1994). When recalls matter: Factors affecting owner response to automotive recalls. Journal of Consumer Affairs, 28(1), 96-107.

ICTI-International Council of Toy Industries (2008). Toy markets in the world. Retrieved from http://www.toy-icti.org /resources/wtf_2008/index.php?slide=6

Jolly, D. W., \& Mowen, J. C. (1985). Product recall communications: The effects of source, media and social responsibility information. Advances in Consumer Research, 12, 471-475.

Klein, J., \& Dawar, N. (2004). Corporate social responsibility and consumers' attributions and brand evaluations in a product-harm crisis. International Journal of Research in Marketing, 21, 203-217.

McIlroy, M. (2007, August 6,). How Mattel can win back parents. Advertising Age (Midwest Edition), 78(31), 8-9.

Mowen, J. C. (1980). Further information on consumer perceptions of product recalls. Advances in Consumer Research, 7 , 519-523.

Mowen, J. C., Jolly, D., \& Nickell, G. S. (1981). Factors influencing consumer responses to product recalls: A regression analysis approach. Advances in Consumer Research, 8, 405-407. 
Schoeny, H. (1992). Koala Springs international product recall. Public Relations Quarterly, 36, 25-26.

Siomkos, G. J., \& Kurzbard, G. (1994). The hidden crisis in product-harm crisis management. European Journal of Marketing, 28, 30-41.

Shrivastava, P., \& Siomkos, G. J. (1989). Disaster containment strategies. Journal of Business Strategy, 10(5), 26-30.

Solomon , M. R., Zaichkowsky, J. L., \& Polegato, R. (2009). Consumer behavior: Buying, having, and being (5th Canadian ed.). Toronto, Ontario: Pearson Education.

Souiden, N. \& Pons, F. (2009). Product recall crisis management: The impact on manufacturer's image, consumer loyalty and purchase intention. Journal of Product and Brand Management, 18(2), 106-114.

Wang, K. Y., Liang, M., \& Peracchio, L. A. (2011). Strategies to offset dissatisfactory product performance: The role of post-purchase marketing. Journal of Business Research, 64, 809-815.

Warner, J. (2008). Mattel's blues. Directorship, 33(6), 30-35.

Xu, J. (2010, October 16). Corporate news: Mattel sales decline sparks holiday worries. Wall Street Journal (Eastern Edition), B3. 